Check for updates

Cite this: RSC Adv., 2019, 9, 19397

Received 8th April 2019

Accepted 13th June 2019

DOI: $10.1039 / c 9 r a 02636 c$

rsc.li/rsc-advances

\section{Preparation and characterization of peptide modified ultrasmall superparamagnetic iron oxides used as tumor targeting MRI contrast agent}

\author{
Jie Yin, (D) ab Guangfu Yin, (D) *a Ximing Pu, (D) ${ }^{a}$ Zhongbing Huang (iD ${ }^{a}$ and Dajin Yao ${ }^{a}$
}

As desirable contrast agents for magnetic resonance imaging (MRI), ultrasmall superparamagnetic iron oxides (USPIOs) are required to exhibit both low cytotoxicity and specific targetability besides superparamagnetism to achieve better imaging contrast at lower dose, and cladding with biocompatible polymers and modification with targeting ligands are considered to be the most effective strategies. In this study, novel dextran wrapped and peptide WSGPGVWGASVK (peptide-WSG) grafted USPIOs were meticulously prepared and systematically characterized. Firstly, dextran (Dex) cladded USPIOs (USPIOs@Dex) were synthesized with a well-designed co-precipitation procedure in which the biocompatible dextran played dual roles of grain inhibitor and cladding agent. After that, sodium citrate was applied to carboxylize the hydroxyls of the dextran molecules via an esterification reaction, and then tumor targeting peptide-WSG was grafted to the carboxyl groups by the EDC method. The XRD, TEM, and FTIR results showed that inverse spinel structure $\mathrm{Fe}_{3} \mathrm{O}_{4}$ crystallites were nucleated and grown in aqueous solution, and the catenulate dextran molecules gradually bound on their surface, meanwhile the growth of grains was inhibited. The size of original crystallite grains was about $7 \mathrm{~nm}$, but the mean size of USPIOs@Dex aggregates was $165.20 \mathrm{~nm}$. After surface modification by sodium citrate and peptide-WSG with ultrasonic agitation, the size of the USPIOs@Dex-WSG aggregates was smaller $(66.06 \mathrm{~nm})$ because the hydrophilicity was improved, so USPIOs@Dex-WSG could evade being eliminated by RES more easily, and prolong residence time in blood circulation. The VSM and $T_{2}$-weighted MRI results showed that USPIOs@Dex-WSG were superparamagnetic with a saturation magnetization of $44.65 \mathrm{emu} \mathrm{g}^{-1}$, and with high transverse relaxivity as the $R_{2}$ relaxivity coefficient value was $229.70 \mathrm{mM}^{-1} \mathrm{~s}^{-1}$. The results of MTT assays and the Prussian blue staining in vitro revealed that USPIOs@Dex-WSG exhibited nontoxicity for normal cells such as L929 and HUVECs, and were specifically targeted to the SKOV-3 cells. Thus, the novel dextran wrapped and WSGpeptide grafted USPIOs have potential to be applied as tumor active targeting contrast agents for MRI.

\section{Introduction}

In the past decades, molecular imaging techniques have been rapidly developed for the detection and diagnosis of early stage tumors. $^{1-3}$ Among the clinical imaging methods, magnetic resonance imaging (MRI) is an efficient and noninvasive technique because of its tomographic capabilities and high resolution. ${ }^{4,5}$ However, the image contrast of the tumor site in MRI is not high enough for diagnosis frequently in clinical application; so contrast agents, which can change the longitudinal relaxation time $\left(T_{1}\right)$ or the transverse relaxation time $\left(T_{2}\right)$, are important to improve the imaging sensitivity between tumor and surrounding normal tissues. $T_{1}$ contrast agent, known as

${ }^{a}$ College of Materials Science and Engineering, Sichuan University, No. 24, South 1st Section, 1st Ring Road, Chengdu, 610065, PR China. E-mail: nic0700@scu.edu.cn; Fax: +86-28-85413003; Tel: +86-28-85413003

${ }^{b}$ School of Automation and Information Engineering, Sichuan University of Science and Engineering, Zigong, 643000, PR China positive contrast agent, mainly refers to gadolinium agent which can brighten images of relevant parts, but their side effects have been found to cause nephrogenic systemic fibrosis in some cases. $T_{2}$ contrast agents based on ultrasmall superparamagnetic iron oxides (USPIOs), as negative contrast agent, have drawn much attention in biomedical fields for they are biocompatible and nontoxic in appropriate dose..$^{6-9}$

Iron oxide particles less than $25 \mathrm{~nm}$ are single magnetic domains for the lowest free energy, so USPIOs are superparamagnetic with high relaxation rate, they can shorten $T_{2}$ and decrease magnetic resonance signal to darken the images of the relevant parts. USPIOs synthesized by chemical coprecipitation methods have been widely used because of their small particle size, and the process involves initial nucleation followed by slow growth as the solutes diffuse to the surface of the crystal. USPIOs should be hydrophilic and biocompatible in biomedical applications, and be small enough to evade eliminated by reticuloendothelial system (RES); but USPIOs without wrappers would reunite spontaneously and form large aggregates because 
of the high surface energy. ${ }^{\mathbf{1 0}}$ So the surface modification is necessary for USPIOs to enhance the steric hindrance effect, improve the hydrophilicity and dispersibility under physiological conditions, and prolong circulation time in the blood. Then, USPIOs modified with biocompatible agents have attracted increasing attention. ${ }^{\mathbf{1 1 , 1 2}}$ As a frequently-used agent, dextran molecules are polysaccharides with branched chains of hydroxyl, and $\mathrm{Fe}_{3} \mathrm{O}_{4}$ particles can be wrapped and restricted by dextran molecules. Many commercial $T_{2}$ contrast agents, such as Feridex and AMI-25, are wrapped by dextran molecules because they not only protect iron oxide nanoparticles, but also make them hydrophilic and biocompatible. ${ }^{\mathbf{1 3 , 1 4}}$

Currently, $T_{2}$ contrast agents enter organs passively according to their particle sizes and surface properties in clinical application; so their distributions mainly focus in the organs with abundant blood flow and macrophages, such as liver and spleen. However, their distributions would be much lower in the tumors of organs with less blood flow. So functional USPIOs modified with specific ligands can improve the collection in tumor regions, change the distribution of USPIOs in the body, and reduce the usage amount of iron oxide to avoid potential organ damage by excessive iron intake. ${ }^{15-17}$ The targeting ligands, such as peptides and other biological molecules, can bind with the specific protein receptors of tumor cells. Peptide WSGPGVWGASVK (abbreviated as peptide-WSG) was isolated from nude mice bearing human ovarian carcinoma xenografts with in vivo phage peptide display method, and whose targeting properties to ovarian carcinoma cells SKOV-3 have been verified in vitro and in vivo in our previous works. ${ }^{18}$ Peptide-WSG were detected to locate in cytoplasma and nucleus by immunofluorescence as an ideal candidate for ovarian cancer targeting peptide, and presented inhibitory effect in cell-cellular matrix adhesion assay, which was inferred to be involved in ovarian cancer metastasis. Peptides are usually bound to polymers by amide bond or maleimide bond, but there aren't suitable functional groups on USPIOs or dextran, so the dextran molecules around USPIOs should be further modified with carboxyl to link to peptide-WSG by amido linkage.

In order to develop a new MRI contrast agent with active targetability for ovarian tumor in this study, USPIOs were synthesized by chemical coprecipitation methods in dextran wrappers (abbreviated as USPIOs@Dex), and the influence factors in the synthesis process of USPIOs@Dex were analyzed contrastively to search the optimal preparation scheme. Then USPIOs@Dex were carboxylated by sodium citrate, and then peptide-WSG was bound with the carboxyls by EDC method, the schematic illustration of these surface modifications were shown in Fig. 1. Then the magnetic performance, relaxation rate, cytotoxicity and targetability for SKOV-3 tumor cells were investigated to examine the potential of USPIOs@Dex-WSG for targeting MRI contrast agent. ${ }^{19-25}$

\section{Materials and method}

\section{Materials and reagents}

Ferric chloride $\left(\mathrm{FeCl}_{3} \cdot 6 \mathrm{H}_{2} \mathrm{O}\right)$, ferrous chloride $\left(\mathrm{FeCl}_{2} \cdot 4 \mathrm{H}_{2} \mathrm{O}\right)$, sodium hydroxide, sodium citrate, ethylene diaminetetraacetic

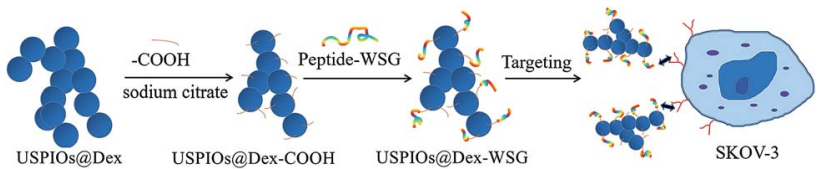

Fig. 1 Schematic illustration for surface modifications of USPIOs@Dex with peptide-WSG.

acid (EDTA), hydrochloric acid and dimethylsulphoxide (DMSO) were purchased from Kelong Chemical Co. (Chengdu, China, AR). Dextran T20 and T40 (20 kDa and $40 \mathrm{kDa}$ ), 1-ethyl-3-[3(dimethylamino)propyl]carbodiimide hydrochloride (EDC), $\mathrm{N}$ hydroxysuccinimide (NHS), 2-( $N$-morpholino) ethanesulfonic acid were purchased from Aladdin (Shanghai, China). PeptideWSG was synthesized by Shanghai Bootech Bioscience and Technology Co., Ltd. (Shanghai, China).

The mouse fibroblasts cells (L929), human umbilical vein cell line (HUVEC) and ovarian carcinoma cells (SKOV-3) were obtained from West China School of Basic Medical Sciences and Forensic Medicine, Sichuan University (Chengdu, China). The cells were respectively cultured in DMEM and RPMI 1640 (Gibco, USA) medium under a $5 \% \mathrm{CO}_{2}$ atmosphere at $37{ }^{\circ} \mathrm{C}$.

\section{Synthesis of USPIOs@Dex}

USPIOs@Dex were synthesized by chemical coprecipitation method with dextran. Concretely, $\mathrm{FeCl}_{3} \cdot 6 \mathrm{H}_{2} \mathrm{O}(0.32 \mathrm{~g})$ and $\mathrm{FeCl}_{2} \cdot 4 \mathrm{H}_{2} \mathrm{O}(0.19 \mathrm{~g})$ were dissolved in the deoxidizing water (30 $\mathrm{mL}$ ) stirring at $50{ }^{\circ} \mathrm{C}$ under $\mathrm{N}_{2}$ atmosphere to avoid oxidation. Then, a preseted amount of dextran T20 or dextran T40 was added to the solution for $2 \mathrm{~h}$ to form solution. After that, $5 \mathrm{~mL}$ of $\mathrm{NaOH}(1 \mathrm{M})$ was rapidly dripped to the above solution with mechanical agitation of $1000 \mathrm{rpm}$. The dark green viscous solution was ripened for $1 \mathrm{~h}$, and the obtained black suspension was centrifuged at $8000 \mathrm{rpm}$ for $5 \mathrm{~min}$. Then the upper layer suspension was further treated by ultracentrifugation in 100 kDa molecular weight cutoff filtering column (Amicon, Millipore Corporation) at $3000 \mathrm{rpm}$ for $40 \mathrm{~min}$, to remove unreacted $\mathrm{NaOH}$ and unbound dextran. The obtained products were the suspension of USPIOs wrapped with dextran (denoted as USPIOs@Dex). The influences of the dextran molecular weight (20 kDa, $40 \mathrm{kDa})$, dextran contents $\left(20 \mathrm{mg} \mathrm{mL}^{-1}, 40 \mathrm{mg} \mathrm{mL}^{-1}\right.$, $60 \mathrm{mg} \mathrm{mL}^{-1}$ and $80 \mathrm{mg} \mathrm{mL}^{-1}$ ), and the reaction temperature $\left(50{ }^{\circ} \mathrm{C}, 60{ }^{\circ} \mathrm{C}, 70{ }^{\circ} \mathrm{C}, 80^{\circ} \mathrm{C}\right)$ would be investigated.

\section{Surface modification of USPIOs@Dex with sodium citrate and peptide-WSG}

In order to conjugate with peptide-WSG, USPIOs@Dex were carboxylated via grafting carboxyl groups onto the dextran molecules around iron oxides. Firstly, $100 \mathrm{~mL}$ USPIOs@Dex suspension $\left(0.7 \mathrm{mg} \mathrm{Fe} \mathrm{mL}^{-1}\right)$ was pretreated by ultrasonic agitation under $\mathrm{N}_{2}$ environment to avoid oxidation, and $100 \mathrm{~mL}$ sodium citrate solution $\left(1 \mathrm{mg} \mathrm{mL}^{-1}\right)$ was slowly added to the suspension. The mixture was ultrasonicated and stirred for 12 hours to graft carboxylate onto the USPIOs@Dex. Then, the suspension was treated by ultracentrifugation $(3000 \mathrm{rpm}, 40$ min) in $100 \mathrm{kDa}$ molecular weight cutoff filtering column for 3 
times to remove unreacted sodium citrate, and USPIOs@Dex$\mathrm{COOH}$ suspension was synthesised.

The peptide-WSG was conjugated on the USPIOs@Dex$\mathrm{COOH}$ by the EDC method. EDC $(9.2 \mathrm{mg})$ and NHS $(5.5 \mathrm{mg})$ were dispersed in USPIOs@Dex-COOH suspension under the ultrasound agitation at room temperature for $2 \mathrm{~h}$ to activate the carboxyl groups of USPIOs@Dex-COOH. Then, peptide-WSG (40 $\mathrm{mg}$ ) was dispersed in the mixture under the ultrasound agitation at room temperature for $12 \mathrm{~h}$. Finally, the products (denoted as USPIOs@Dex-WSG) were purified by ultracentrifugation (3000 rpm, $40 \mathrm{~min}$ ) in $100 \mathrm{kDa}$ molecular weight cutoff filtering column for 3 times.

\section{Characterization of USPIOs}

The morphologies of the prepared USPIOs were observed by the transmission electron microscopy (TEM, LIBRA 200FE, Carl Zeiss SMT Pte Ltd., Germany). X-ray diffraction (XRD) patterns were recorded on a Bruker D8-Advance diffractometer $(\mathrm{Cu} \mathrm{K} \alpha, \lambda$ $=1.54178 \AA$ ), and Fourier transform infrared (FTIR) spectra were obtained on a Shimadzu IR Prestige-21 spectrometer. Thermogravimetry (TG/SDTA 851e analyzer of METTLERTOLEDO Co., Switzerland) was utilized to analyze the proportion and thermal properties of the product. The hydrodynamic sizes and apparent zeta potentials of the USPIOs were measured by Zetasizer Nano ZS (Malvern Panalytical Ltd., UK). Nitrogen contents were measured by elemental analyser (EA3000, Euro Vector, Italy) for USPIOs@Dex-WSG and the USPIOs disposed by EDC/NHS but without peptide-WSG. The magnetic properties of the USPIOs were measured by the vibrating sample magnetometer (VSM, Lake shore-7400, USA) at room temperature.

The MR imaging was measured by a 7.0 $\mathrm{T}$ system (Biospec 70/30 USR MRI scanner, Germany). Series of USPIOs with iron concentrations of $0.035,0.07,0.14,0.28$ and $0.56 \mathrm{mM}$ were dispersed in aqueous medium. An inversion recovery sequence with constant repetition time (TR) and echo time (TE) of 3163.9 and $22 \mathrm{~ms}$ respectively with varying inversion time $\left(T_{\mathrm{I}}\right)$ of 50 to $3000 \mathrm{~ms}$ were used for calculating longitudinal relaxation rate $\left(r_{1}\right)$. A modified transverse relaxometry spin echo sequence with TR of $3163 \mathrm{~ms}$ with varying TE from 11 to $110 \mathrm{~ms}$ was used for getting transverse relaxation rate $\left(r_{2}\right)$. Pixel intensity with respect to each concentration was extracted from the MR images. Signal intensity against $T_{\mathrm{I}}$ and TE values were plotted for getting $T_{1}$ and $T_{2}$ relaxation times respectively. Likewise, $T_{1}$ and $T_{2}$ relaxation times for different concentration were obtained. These values were plotted against the iron concentrations. Longitudinal and transverse relaxation values $\left(r_{1}\right.$ and $\left.r_{2}\right)$ were calculated by the linear fit. ${ }^{21}$

\section{Cytotoxicity assay}

To evaluate the cytotoxicity of USPIOs@Dex-WSG, MTT assays were performed to quantify the influences of USPIOs@Dex-WSG on the viability of HUVECs and SKOV-3. The logarithmic phase cells were grown in 96-well plates, when the cells reached confluence, suspensions of USPIOs@Dex-COOH and USPIOs@Dex-WSG with different concentrations $(25,50,100$ and $200 \mu \mathrm{g} \mathrm{mL}^{-1}$ ) were respectively added to each well and then were co-cultured $\left(5 \% \mathrm{CO}_{2}, 37^{\circ} \mathrm{C}\right)$. Meanwhile, cells without any USPIOs were chosen as a control. After $12 \mathrm{~h}, 24 \mathrm{~h}$, and $36 \mathrm{~h}$ incubation, $\quad 20 \quad \mu \mathrm{L} \quad 3$-(4,5-dimethylthiazol-2-yl)-2,5diphenyltetrazolium bromide (MTT) solution $\left(5 \mathrm{mg} \mathrm{mL}^{-1}\right)$ were added to each well and incubated for another $4 \mathrm{~h}$. After the nutrient solution was extracted, $150 \mu \mathrm{L}$ dimethyl sulfoxide (DMSO) was poured into each well under the low-speed oscillation on the table concentrator (HZ-9210K). The optical density (OD) of each well was measured by a microplate reader (Molecular Devices, VM, USA) at $490 \mathrm{~nm}$. The cell viability was calculated by the following formula:

cell viability $(\%)=$ optical density $(\mathrm{OD})$ of the treated cells/OD of the untreated cells

\section{Tumor specific affinity assay}

The targeting effect of USPIOs@Dex-WSG was determined by the Prussian blue staining. SKOV-3, HUVEC and L929 cells were respectively inoculated on the 24-well plate. USPIOs@Dex$\mathrm{COOH}$ and USPIOs@Dex-WSG were diluted by the serum-free medium respectively, then co-cultured with attached cells for 4 hours, the nutrient solution was extracted and cells were washed twice by PBS. After $4 \%$ paraformaldehyde $(400 \mu \mathrm{L})$ were added in each well to fix cells for $10 \mathrm{~min}$, the fixative was sucked out and air dried for $10 \mathrm{~min}$. After that, the materials were soaked by PBS $(400 \mu \mathrm{L})$ for $5 \mathrm{~min}$ and then extracted solution. $2 \%$ potassium ferrocyanide and $2 \%$ hydrochloric acid were mixed $(1: 1)$ and added to cell culture plate ( $400 \mu \mathrm{L}$ per well), staining for $30 \mathrm{~min}$ at room temperature. When the staining finished, the staining solution was sucked out and the cells were washed three times by the PBS solution. The samples were respectively observed by microscope and the results were recorded. ${ }^{13}$

\section{Statistical analysis}

Statistical analysis was carried out with the Statistical Package for the Social Sciences (SPSS) version 13.0 software, data were expressed as means \pm standard deviations, and $p<0.05$ was considered as statistically significant. Statistical comparisons were performed by analysis of variance (ANOVA).

\section{Plasma half-life assay}

Six healthy rabbits $(2-3 \mathrm{~kg})$ were randomly divided into two group, and injected via ear veins with USPIOs@Dex and

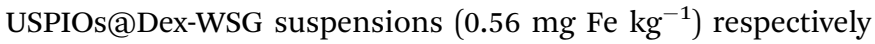
after abrosia with free access to water for $12 \mathrm{~h} .150 \mu \mathrm{L}$ of blood samples were collected before injection and at $15 \mathrm{~min}, 1 \mathrm{~h}, 2 \mathrm{~h}$, $4 \mathrm{~h}, 8 \mathrm{~h}, 12 \mathrm{~h}$ and $24 \mathrm{~h}$ after injection, then digested with nitric acid and perchloric acid. The iron contents in the blood samples (abbreviated as $C$ ) were measured by ICP-AES, and the iron content before injection was denote as $C_{0}$. Taking the time as the horizontal axis and the difference value of $\left(C-C_{0}\right)$ as the vertical axis, the plasma half-life was calculated with the curve fitted by single exponential decreasing function. 


\section{Results and discussions}

\section{Optimization of USPIOs@Dex synthesis process}

It was generally known that the formation of nanoparticles by coprecipitation method was controlled by confinement effect in micelles made of catenulate molecules, so the formation of micelles would be the prerequisite of the regulation in coprecipitation. In order to find the suited dextran molecular weight, dextran T20 and T40 were dissolved respectively in double distilled water $\left(40 \mathrm{mg} \mathrm{mL}^{-1}\right)$ to prepare the magnetic particles in the reaction temperature $80{ }^{\circ} \mathrm{C}$. The TEM images of USPIOs@Dex were shown in Fig. 2. Because abundant sodium hydroxide was rapidly dripped to the two solutions respectively with mechanical agitation, the crystal nucleus generated more quickly than the growth, then more and smaller crystallites were produced and restricted by the dextran chains wrapped around them. Therefore, the single nanoparticle synthesized with dextran T20 and T40 were both about $7 \mathrm{~nm}$ in size identically. Nevertheless, the results also showed that there were obvious differences in the length and distribution of the nanoparticle chains. The nano-chains prepared with dextran T20 (shown in Fig. 2a and b) were about 100-200 nm, distributed uniformly in the collosol. Conversely, the chains with dextran T40 (shown in Fig. 2c and d) were over $200 \mathrm{~nm}$ long and interweaved with each other to form nets owing to the higher molecular weight and longer molecular chain of dextran T40. It can be speculated that the length and network of the iron oxide particle chains would aggravate if the dextran of even higher molecular weight had been applied as the coating agent. ${ }^{13}$

TG analysis of synthesized USPIOs@Dex was carried out to further verify that the dextran T20 and dextran T40 were both successfully coated to nanoparticles, and the TG curves were shown in Fig. 3. The weight loss of $8.7 \%$ before $200{ }^{\circ} \mathrm{C}$ was

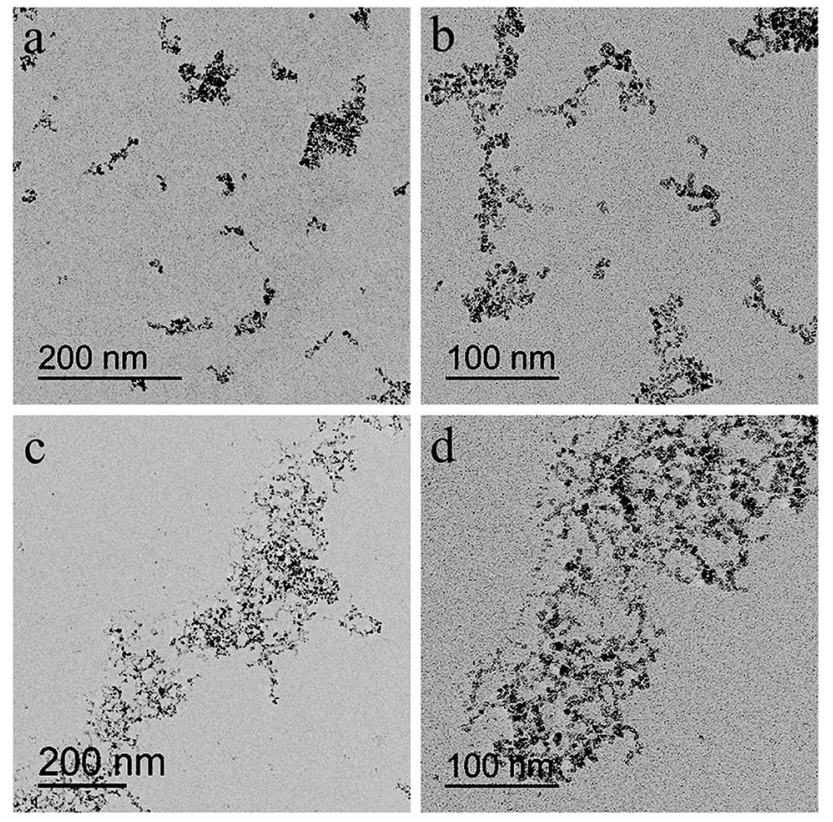

Fig. 2 TEM images of USPIOsaDex synthesized with $40 \mathrm{mg} \mathrm{mL}^{-1}$ dextran T20 ( $a$ and b) and dextran T40 (c and d) at $80^{\circ} \mathrm{C}$.

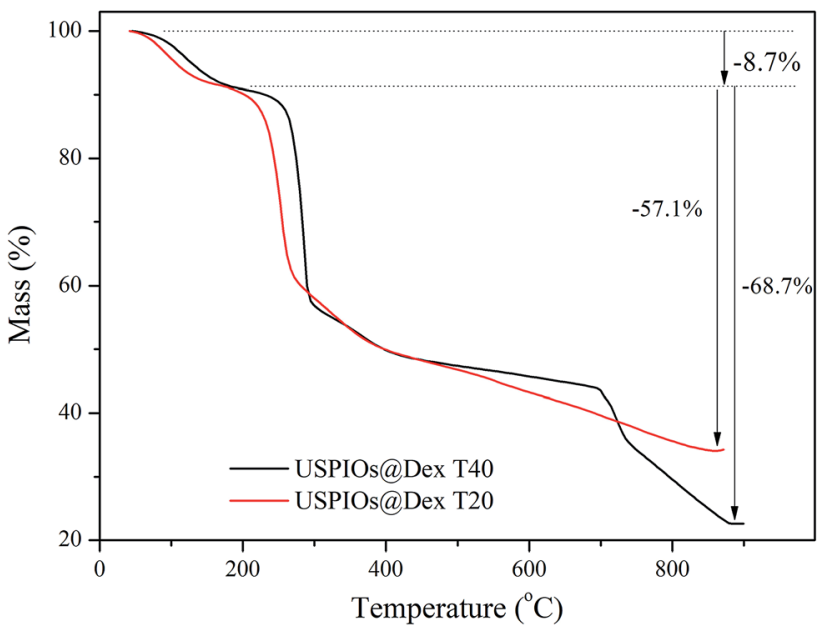

Fig. 3 TG analysis of USPIOs@Dex synthesized with $40 \mathrm{mg} \mathrm{mL}^{-1}$ dextran $\mathrm{T} 20$ and dextran $\mathrm{T} 40$ at $80{ }^{\circ} \mathrm{C}$.

attributed to the adsorbed water on the USPIOs@Dex, and the weight loss from $200{ }^{\circ} \mathrm{C}$ to $900{ }^{\circ} \mathrm{C}$ was resulted from the thermal decomposition of dextran. The results also demonstrated that the proportion of dextran T40 was $68.7 \%$ in the synthesized nanoparticles, less than the proportion of 57.1\% in USPIOs@Dex synthesized with dextran T20. Because of the larger molecular weight, the molecular chain of dextran T40 is longer than dextran T20, and then the proportion of dextran T40 in USPIOs@Dex was higher. Accordingly, the proportion decrease of iron oxide, which was the effective ingredient for MRI enhancing, would reduce the effect of the contrast agent.

It is well known that the size of particles influence the remaining time in blood circulation because the particles larger than $100 \mathrm{~nm}$ would be removed by phagocytosis in the mononuclear phagocyte system (MPS) of liver and spleen. The USPIOs@Dex synthesized by dextran T40 were more than $100 \mathrm{~nm}$ in total size apparently, and the proportion of dextran T40 in USPIOS was higher than dextran T20, so dextran T40 was not suitable for magnetic resonance probes of ovarian tumor targeting. Then the USPIOs@Dex synthesized with dextran T20 would be analyzed for the advantages: smaller size, shorter length and less dextran proportion in USPIOs@Dex.

To discover the influence of concentration range, the USPIOs@Dex were synthesized with different dextran T20 concentrations respectively $\left(20 \mathrm{mg} \mathrm{mL}^{-1}, 40 \mathrm{mg} \mathrm{mL}^{-1}, 60 \mathrm{mg}\right.$ $\mathrm{mL}^{-1}$, and $80 \mathrm{mg} \mathrm{mL}{ }^{-1}$ ) at $80{ }^{\circ} \mathrm{C}$, and the TEM images of USPIOs@Dex were shown in Fig. 4. The USPIOs@Dex synthesized with dextran $\mathrm{T} 20$ of $20 \mathrm{mg} \mathrm{mL}^{-1}$ were shown in Fig. 4a, the nonuniform morphology and size were observed in the yellow circle, and these USPIOs@Dex agglomerated together for the insufficient of coating agent. Whereas, the USPIOs@Dex synthesized with dextran T20 concentration of $40 \mathrm{mg} \mathrm{mL} \mathrm{m}^{-1}$ (Fig. 4b) exhibited the short nano-chains with globular particles of similar shape and uniform size (diameter of $\sim 7 \mathrm{~nm}$ ). And it was analogous in dextran T20 concentration up to $60 \mathrm{mg} \mathrm{mL}^{-1}$ (Fig. 4c), the particle size of the spherical nanoparticle was still about $7 \mathrm{~nm}$, but the chain length was longer because of the aggrandized dextran concentration. However, with the further 

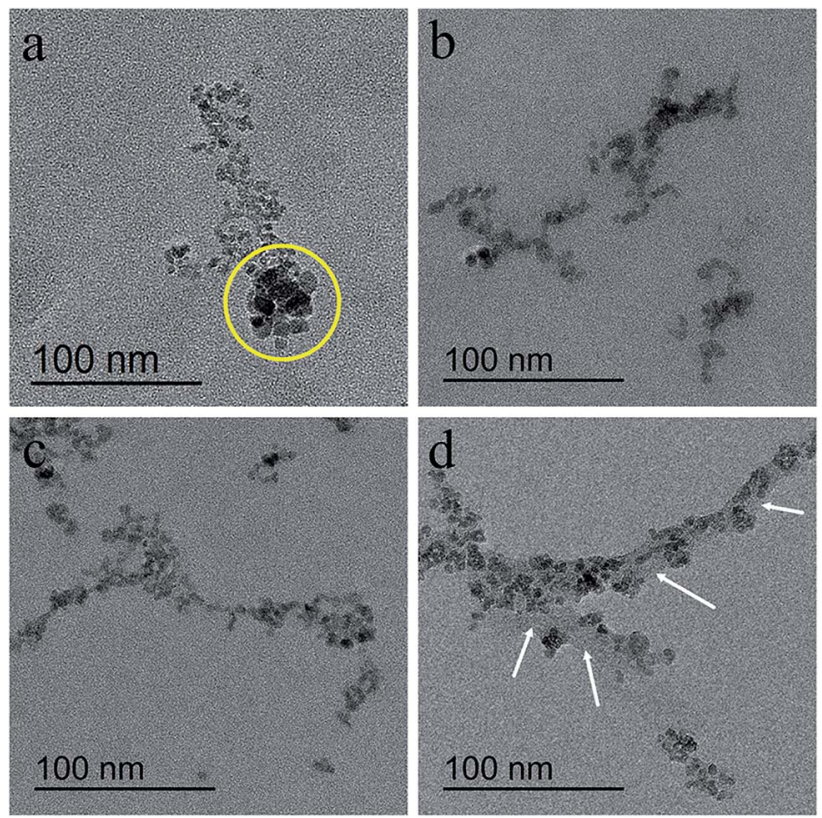

Fig. 4 TEM images of USPIOs aDex synthesized with different dextran T20 concentrations of $20 \mathrm{mg} \mathrm{mL}^{-1}$ (a), $40 \mathrm{mg} \mathrm{mL}^{-1}$ (b), $60 \mathrm{mg} \mathrm{mL}^{-1}$ (c), and $80 \mathrm{mg} \mathrm{mL}^{-1}$ (d) at $80^{\circ} \mathrm{C}$.

increase of dextran T20 concentration to $80 \mathrm{mg} \mathrm{mL}^{-1}$ (Fig. 4d), $\mathrm{Fe}_{3} \mathrm{O}_{4}$ particles were connected by too much dextran as shown by white arrows.

Dextran molecules are chain-like structure with a large number of hydrophilic hydroxyl groups. When dextran was dissolved in water, these hydroxyl groups formed hydrogen bonds with oxygen atoms of water molecules. After agitation, the flexible dextran molecular chains were bent and dispersed in water evenly, then $\mathrm{NaOH}$ was added to the mixed solution of iron salt and dextran, $\mathrm{Fe}_{3} \mathrm{O}_{4}$ crystal nucleus were produced. When $\mathrm{Fe}_{3} \mathrm{O}_{4}$ crystals grew to a certain size, the chance for the contact between them and the dispersed dextran chains increased. Because the hydrogen bond energy between dextran's hydroxyl and the oxygen atom of $\mathrm{Fe}_{3} \mathrm{O}_{4}$ is stronger than that of water molecules, some hydroxyl groups would form hydrogen bonds with $\mathrm{Fe}_{3} \mathrm{O}_{4}$ when they were close to the $\mathrm{Fe}_{3} \mathrm{O}_{4}$ crystals, as shown in the schematic illustration in Fig. 5a. Some sinuous parts of the dextran molecules would adhere to the surface of $\mathrm{Fe}_{3} \mathrm{O}_{4}$ crystals via a number of hydrogen bonds between dextran and $\mathrm{Fe}_{3} \mathrm{O}_{4}$. Then, $\mathrm{Fe}_{3} \mathrm{O}_{4}$ particles were wrapped by dextran molecules, and the growth of $\mathrm{Fe}_{3} \mathrm{O}_{4}$ crystals would be inhibited by the dextran wrappers. And the thickness of dextran in USPIOs@Dex was according to the curved length of molecular chains as shown in Fig. 5b. During the growth of $\mathrm{Fe}_{3} \mathrm{O}_{4}$ crystals, one dextran molecule might simultaneously connect with several $\mathrm{Fe}_{3} \mathrm{O}_{4}$ particles via hydrogen bonds, and participated in wrapping several iron oxide nanoparticles; and the dextran molecules would increase the connection density between neighboring particles. Several neighboring $\mathrm{Fe}_{3} \mathrm{O}_{4}$ particles would be linked together by several dextran molecules if the molecular chain was long and concentration was high. Therefore, the larger molecular weighted dextran with longer a
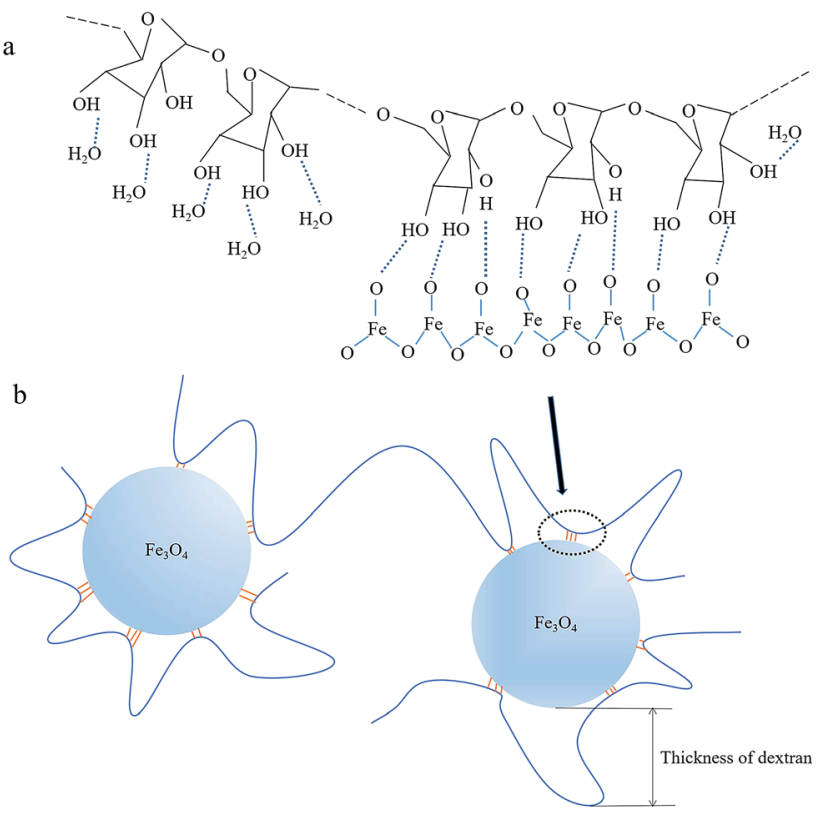

Fig. 5 Schematic illustration for hydrogen bonds between dextran and iron oxide (a); schematic illustration for thickness of dextran in USPIOs@Dex (b).

molecular chains was not suitable for the synthesis of iron oxide nanoparticles; and high concentration of dextran wasn't suitable for the synthesis either.

In this study, the USPIOs@Dex synthesized with dextran T20 in different concentrations by chemical coprecipitation. When the $\mathrm{NaOH}$ solution dropped into the solution of dextran T20 and iron salt, $\mathrm{Fe}_{3} \mathrm{O}_{4}$ crystallites generated and grew; when the crystallites grew to a certain size range, $\mathrm{Fe}_{3} \mathrm{O}_{4}$ particles were constrained by the dextran wrappers. But as shown in the yellow circle of Fig. $4 \mathrm{a}$ with concentration of $20 \mathrm{mg} \mathrm{mL}^{-1}$, the number of dextran molecules was not enough for the $\mathrm{Fe}_{3} \mathrm{O}_{4}$ crystallites, some crystallites weren't wrapped adequately by dextran molecules. Then, some $\mathrm{Fe}_{3} \mathrm{O}_{4}$ nanoparticles grew bigger without uniform spatial constraint, so they were irregular in both granularity and morphology, and agglomerated together because the steric hindrance of dextran between them was feeble. And as shown in Fig. $4 \mathrm{~b}-\mathrm{d}, 40$ and $60 \mathrm{mg} \mathrm{mL}^{-1}$ of dextran were adaptive to synthesizing USPIOs@Dex, but the $\mathrm{Fe}_{3} \mathrm{O}_{4}$ nanoparticles synthesized with $80 \mathrm{mg} \mathrm{mL}^{-1}$ dextran T20 were connected by too much dextran. With the increase of dextran concentration, more and more dextran molecules would adhere to the surface of $\mathrm{Fe}_{3} \mathrm{O}_{4}$ particles via hydrogen bonds between dextran and $\mathrm{Fe}_{3} \mathrm{O}_{4}$, so the dextran wrappers would be thicker and thicker. Consequently, the appropriate concentration of dextran T20 was $40-60 \mathrm{mg} \mathrm{mL}^{-1}$.

The influence of reaction temperature for the USPIOs@Dex was also investigated, and the TEM images of USPIOs@Dex synthesized by dextran $\mathrm{T} 20\left(40 \mathrm{mg} \mathrm{mL}^{-1}\right)$ at different reaction temperature were shown in Fig. 6. Firstly, many acicular particles can be observed in Fig. 6a which were different obviously from spherical $\mathrm{Fe}_{3} \mathrm{O}_{4}$ nanoparticles. For the overdosage of $\mathrm{NaOH}$ was dropped at the reaction temperature $50{ }^{\circ} \mathrm{C}$, acicular 

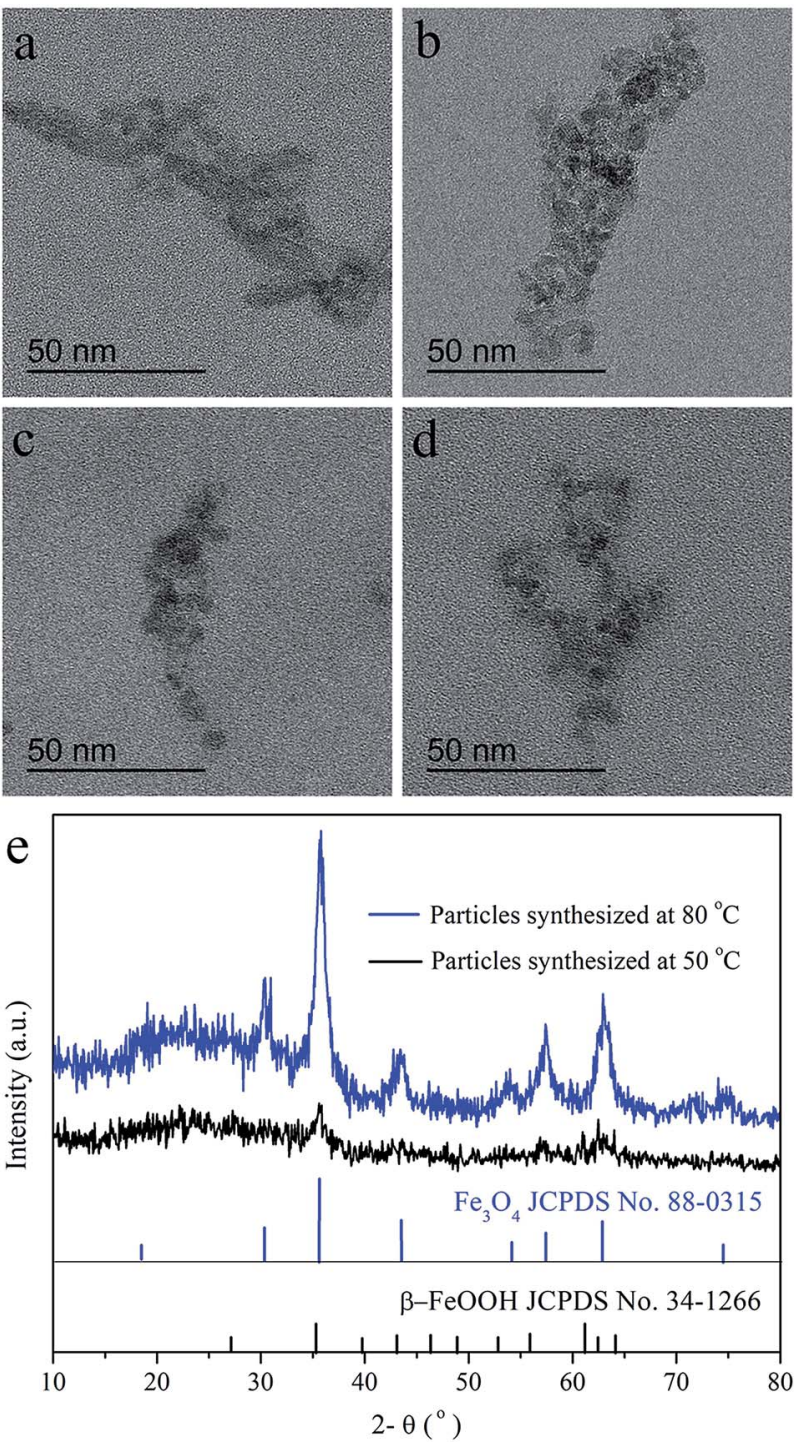

Fig. 6 TEM images of nanoparticles synthesized by dextran T20 (40 $\mathrm{mg} \mathrm{mL}^{-1}$ ) at different reaction temperature of $50^{\circ} \mathrm{C}(\mathrm{a}) ; 60^{\circ} \mathrm{C}(\mathrm{b})$; $70{ }^{\circ} \mathrm{C}$ (c); $80^{\circ} \mathrm{C}$ (d). XRD patterns of particles synthesized with dextran $\mathrm{T} 20\left(40 \mathrm{mg} \mathrm{mL}^{-1}\right)$ at $50{ }^{\circ} \mathrm{C}$ and $80^{\circ} \mathrm{C}(\mathrm{e})$.

$\beta$-FeOOH crystallite was synthesized more competitive than $\mathrm{Fe}_{3} \mathrm{O}_{4}$ crystallite. When the temperature rose to $60^{\circ} \mathrm{C}$, the $\mathrm{Fe}_{3} \mathrm{O}_{4}$ crystallites increased and $\beta$-FeOOH crystallites decreased obviously (Fig. 6b). Eventually, when the solutions were heated up to $70{ }^{\circ} \mathrm{C}$ or $80{ }^{\circ} \mathrm{C}, \mathrm{Fe}_{3} \mathrm{O}_{4}$ nanoparticles coated by dextran were synthesized in suited size without $\mathrm{FeOOH}$ or any other impurities (Fig. 6c and d).

This result was agreed with the XRD patterns of the products synthesized with dextran T20 $\left(40 \mathrm{mg} \mathrm{mL}^{-1}\right)$ at $50{ }^{\circ} \mathrm{C}$ (a) and $80{ }^{\circ} \mathrm{C}(\mathrm{b})$ as shown in Fig. 6e. As discussed above, $\mathrm{Fe}_{3} \mathrm{O}_{4}$ and $\beta$ $\mathrm{FeOOH}$ were both crystallized at $50{ }^{\circ} \mathrm{C}$, so the XRD patterns of the mixed phase were mussy, and the diffraction peaks of the crystallites were observable but not obvious. Nevertheless, the sharpened peaks in XRD pattern of $\mathrm{Fe}_{3} \mathrm{O}_{4}$ crystallite at $80{ }^{\circ} \mathrm{C}$ suggested the higher $\mathrm{Fe}_{3} \mathrm{O}_{4}$ crystal formation degree than at $50{ }^{\circ} \mathrm{C}$.
From the above, the optimal synthetic method for USPIOs@Dex was with dextran T20 $\left(40 \mathrm{mg} \mathrm{mL}^{-1}\right)$ at $80^{\circ} \mathrm{C}$, and the high-resolution TEM (HRTEM) image and FTIR absorption spectra of the USPIOs@Dex were shown in Fig. 7.

It could be observed in the HRTEM that the crystal $\mathrm{Fe}_{3} \mathrm{O}_{4}$ cores with diameter of about $7 \mathrm{~nm}$ (Fig. 7a), and the fringe spacing was about $0.262 \mathrm{~nm}$ coinciding with the (220) crystal plane spacing of $\mathrm{Fe}_{3} \mathrm{O}_{4}$ crystallite. However, the dextran around $\mathrm{Fe}_{3} \mathrm{O}_{4}$ nanoparticle was not obvious (as the white arrow positions) because of the low electron density (Fig. 7b).

The FTIR absorption spectra of dextran and the USPIOs@Dex synthesized by the optimal method were shown in Fig. 7c. The characteristic peaks could be obviously observed in the spectra of USPIOs@Dex, two peeks at around $2931 \mathrm{~cm}^{-1}$ and $1438 \mathrm{~cm}^{-1}$ are stretching vibration peaks of methylene, three peaks at $1151 \mathrm{~cm}^{-1}, 1110 \mathrm{~cm}^{-1}$ and $1014 \mathrm{~cm}^{-1}$ are assigned to the stretching vibration peaks of carbon and oxygen single bond, peaks at $2901 \mathrm{~cm}^{-1}$ and $1371 \mathrm{~cm}^{-1}$ are the stretching vibration peaks of carbon and hydrogen bond, and peaks at $613 \mathrm{~cm}^{-1}$ and $549 \mathrm{~cm}^{-1}$ are the transforming vibration peaks of $\alpha$-pyran ring in the dextran molecules. Furthermore, the stretching vibration peaks of $\mathrm{Fe}-\mathrm{O}$ bond $\left(585 \mathrm{~cm}^{-1}\right)$ was also observed which means there were iron oxide particles in USPIOs@Dex. In consideration of the ultrafiltration for removing the unreacted dextran, the USPIOs@Dex were not simple mixture of dextran and USPIOs. So the results of FTIR
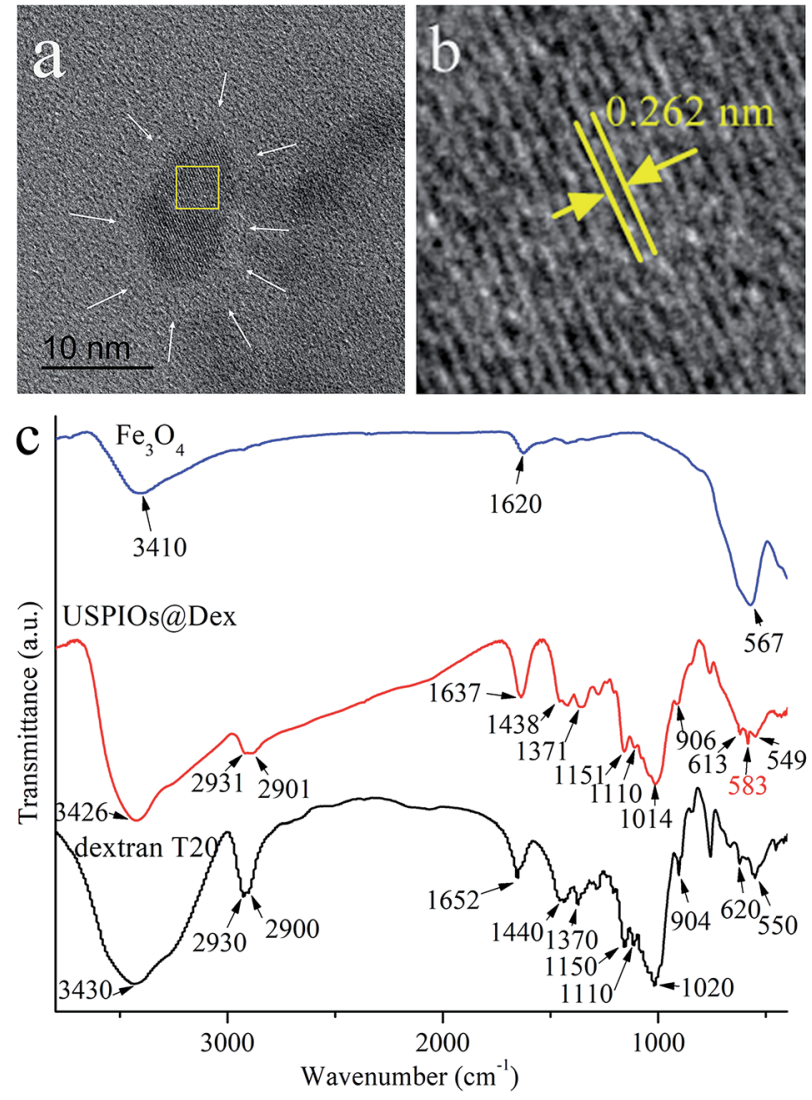

Fig. 7 TEM (a), HRTEM (b) and FTIR absorption spectra (c) of USPIOs@Dex synthesized by optimal method as dextran T20 $(40 \mathrm{mg}$ $\mathrm{mL}^{-1}$ ) at $80^{\circ} \mathrm{C}$. 
absorption spectra, as well as the HRTEM image (Fig. 7a), indicated that the USPIOs were successfully wrapped by the dextran molecules.

\section{Carboxylation of USPIOs@Dex and graft with tumor targeting peptide}

In order to investigate whether the carboxylation of USPIOs@Dex and graft with tumor targeting peptide were successful, FTIR and ultraviolet-visible absorption spectra were analyzed further. The FTIR absorption spectra of the USPIOs@Dex, USPIOs@Dex-COOH, USPIOs@Dex-WSG and peptide-WSG were shown in Fig. 8a. Comparing with the spectrum of the USPIOs@Dex, the characteristic peaks could be obviously observed in the spectrum of USPIOs@Dex-COOH; peak at around $1730 \mathrm{~cm}^{-1}$ is the vibration peak of $\mathrm{C}=\mathrm{O}$ bond, two peaks at $1402 \mathrm{~cm}^{-1}$ and $924 \mathrm{~cm}^{-1}$ are the flexural vibration peaks of $\mathrm{O}-\mathrm{H}$ bond in carboxyl, and the stretching vibration peak of $\mathrm{C}-\mathrm{O}$ bond $\left(1016 \mathrm{~cm}^{-1}\right)$ was observed. For the unreacted sodium citrate had been removed by ultrafiltration, carboxyl have been combined in USPIOs@Dex-COOH. There are three $-\mathrm{COO}^{-}$in the sodium citrate molecule, so the carboxyl
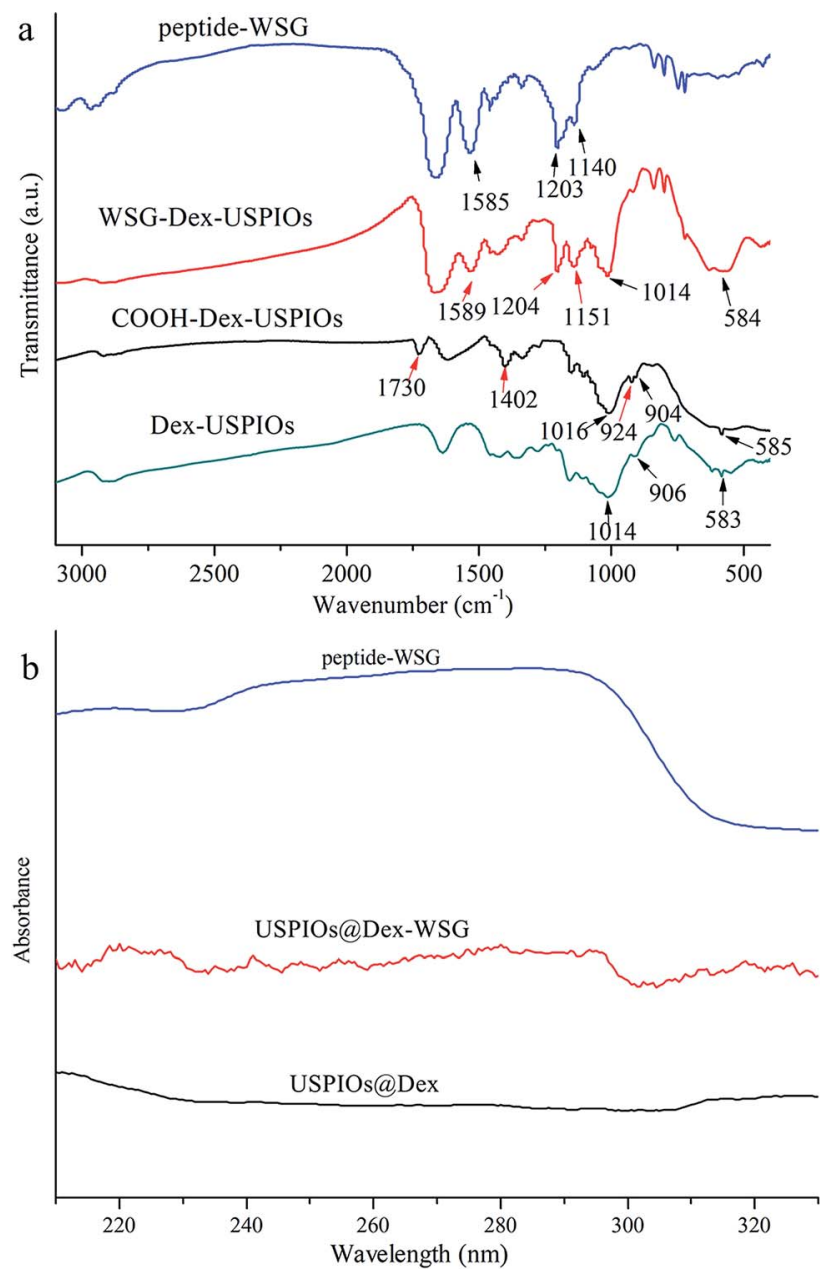

Fig. 8 FTIR (a) and ultraviolet-visible (b) absorbance spectra of peptide-WSG, USPIOs@Dex-WSG, USPIOs@Dex-COOH and USPIOs@Dex. modification might be occurred by hydrogen-bond interaction between the hydroxyls of dextran molecules and the $-\mathrm{COO}^{-}$of sodium citrate. $^{25}$ The carboxylic groups of citrate also likely replaced the hydroxyl groups of the dextran on the surface of $\mathrm{Fe}_{3} \mathrm{O}_{4}$. And then, the uncombined carboxyl of sodium citrate would be retained on the surface of USPIOs@Dex-COOH as shown in the first step of Fig. 9.

EDC method was applied to active carboxylic group because the carbonized diimine molecule has a positive charge with strong chemical reactivity, NHS was applied to stable the intermediates; and then, amido bond was formed between the intermediates and peptide-WSG, as shown in Fig. 9. The FTIR absorption spectra of USPIOs@Dex, USPIOs@Dex-COOH, USPIOs@Dex-WSG and peptide-WSG were shown in Fig. 8a. The stretching vibration peak of $\mathrm{C}-\mathrm{O}$ bond $\left(1014 \mathrm{~cm}^{-1}\right)$ and the stretching vibration peak of $\mathrm{Fe}-\mathrm{O}$ bond $\left(585 \mathrm{~cm}^{-1}\right)$ were also observed. Furthermore, peak at $1589 \mathrm{~cm}^{-1}$ was the absorption peak of aromatic ester in tryptophan (abbreviated as $\mathrm{W}$ ); and two peaks at around $1204 \mathrm{~cm}^{-1}$ and $1151 \mathrm{~cm}^{-1}$ were the stretching vibration peaks of $\mathrm{C}-\mathrm{N}$ bonds which were contained in the aliphatic amines such as glycine (G), alanine (A) and valine $(\mathrm{V})$ in the peptide WSGPGVWASVK. For unreacted peptide-WSG had been eliminated by ultrafiltration, peptideWSG combined to surface of USPIOs@Dex-COOH.

Ultraviolet-visible absorbance spectra were applied to further confirm the success of surface modification of peptide-WSG (Fig. 8b). Compared with the spectrum of peptide-WSG, the peak was also at around $286 \mathrm{~nm}$ and then declined sharply from 290 to $300 \mathrm{~nm}$ in the spectrum of USPIOs@Dex-WSG, which was the absorption peak of tryptophan (W) in peptide

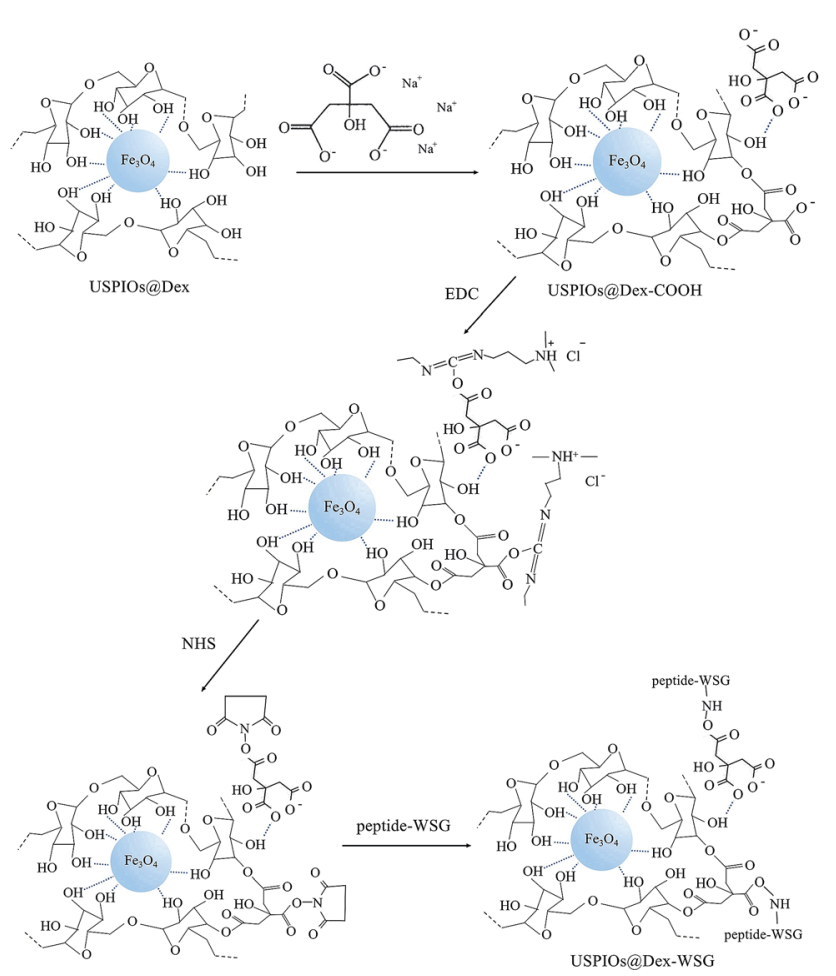

Fig. 9 Schematic illustration of targeting modifications for USPIOs@Dex. 
WSGPGVWGASVK. Because unreacted peptide-WSG was eliminated by ultrafiltration, it indicated that peptide-WSG had been bound in USPIOs@Dex-WSG.

Nitrogen weight contents were measured for USPIOs@DexWSG $(1.872 \%)$ and the USPIOs disposed by the same method of EDC/NHS without peptide-WSG (1.396\%). To exclude the content of nitrogen element in EDC/NHS and the air absorbed in USPIOs, the difference value $(0.476 \%)$ was calculated and then divided by the nitrogen contents in peptide-WSG molecule $(14.716 \%)$, it could be get to know the percentage content of peptide-WSG conjugated in USPIOs@Dex-WSG was about $3.234 \%$.

Then, the TEM images, hydrodynamic size distributions and apparent zeta potentials of USPIOs@Dex, USPIOs@Dex-COOH, USPIOs@Dex-WSG were shown in Fig. 10. It could be observed in Fig. 10b and $\mathrm{c}$ that the two modified groups of USPIOs@Dex$\mathrm{COOH}$ and USPIOs@Dex-WSG were both smaller than USPIOs@Dex (Fig. 10a), while the single $\mathrm{Fe}_{3} \mathrm{O}_{4}$ particle size didn't change observably. And the mean hydrodynamic size of USPIOs@Dex was $165.20 \mathrm{~nm}$, while the mean hydrodynamic size of USPIOs@Dex-COOH and USPIOs@Dex-WSG were $61.98 \mathrm{~nm}$ and $60.66 \mathrm{~nm}$ respectively (Fig. 10d-f). Because the hydrophilicity of nano-chains was enhanced after surface modification, USPIOs@Dex were disintegrated. Then, USPIOs@Dex-WSG and USPIOs@Dex-COOH were smaller in size, easier to evade from eliminated by RES, and to prolong residence time in blood circulation.

Nevertheless, the surface charges of the nano-chains reduced as the decreasing of size. As shown in Fig. 10g-i, the apparent zeta potential of USPIOs@Dex was $-35.3 \mathrm{mV}$, it was stable relatively in aqueous solution, while the apparent zeta potentials of USPIOs@Dex-COOH and USPIOs@Dex-WSG were $-26.1 \mathrm{mV}$ and $-15.7 \mathrm{mV}$ respectively. The absolute values of the apparent zeta potentials decreased after surface modification, but the surface charge were still negative, then the electrostatic repulsion between nano-chains decreased a bit, which might

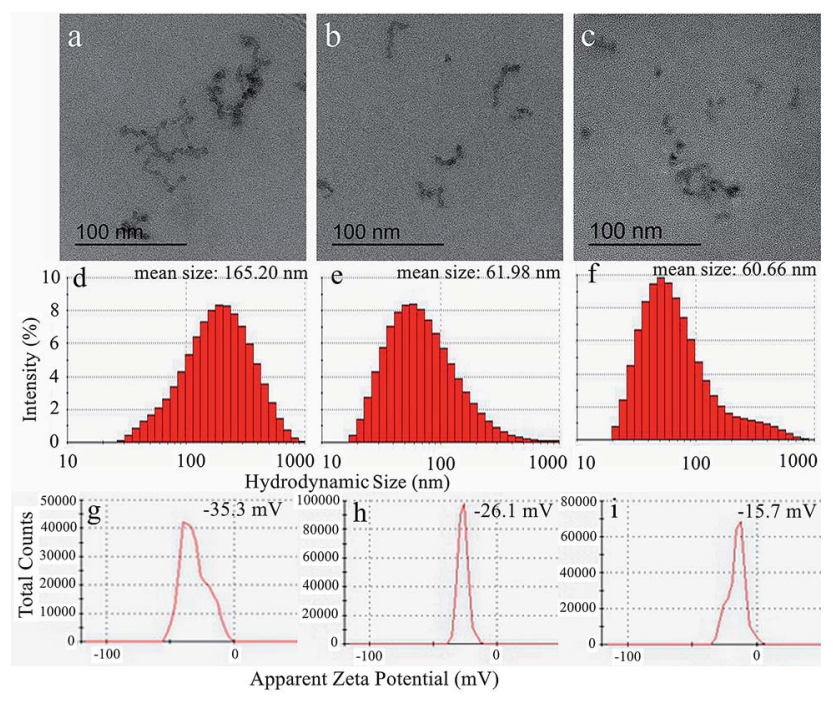

Fig. 10 TEM images $(a-c)$, hydrodynamic size distributions $(d-f)$ and apparent zeta potentials $(\mathrm{g}-\mathrm{i})$ of USPIOs@Dex, USPIOs@Dex-COOH and USPIOs@Dex-WSG respectively. mean the dispersion stability of USPIOs@Dex-WSG in aqueous solution was lower than USPIOs@Dex. So the nano-chains would become weak reunion after long-time immobility, it should be pretreated by ultrasound for dispersion before applications. But on the other hand, nano-chains with less surface charge were less adsorption of substances in the blood after they were injected into the body intravenously, it also could prolong the residence time in blood circulation.

\section{Performances of USPIOs@Dex-WSG as tumor targeted MRI contrast agent}

To discuss the performance as tumor targeted MRI contrast agent, the relaxivity, cytotoxicity and targetability of USPIOs@Dex-WSG should be investigated. The hysteresis loops of USPIOs@Dex and USPIOs@Dex-WSG were shown in Fig. 11a. In the magnetization curves, saturation magnetization of USPIOs@Dex-WSG was $44.65 \mathrm{emu}^{-1}$, the magnetic property did not change obviously after surface modification, for there was just little decrease comparing with $46.51 \mathrm{emu}^{-1}$ of USPIOs@Dex. And the coercivities $\left(H_{\mathrm{c}}\right)$ were less than $10 \mathrm{Oe}$, almost negligible coercivity indicated their superparamagnetic behavior. Because the inner magnetic domain wall is unstable when $\mathrm{Fe}_{3} \mathrm{O}_{4}$ nanoparticles are less than $20 \mathrm{~nm}$, the particles tend to be single magnetic domain with superparamagnetism. ${ }^{7}$

As demonstrated in Fig. 11b, the MRI contrast enhancement results of USPIOs@Dex, USPIOs@Dex-COOH and USPIOs@DexWSG observably showed that $T_{2}$ signals reduce with the increase of Fe concentration, but the change between $T_{1}$ signals was not significant. In Fig. 11c, the transverse relaxivity coefficient value $\left(r_{2}\right)$ of USPIOs@Dex, USPIOs@Dex-COOH and USPIOs@DexWSG were 282.96, 251.99 and $229.70 \mathrm{mM}^{-1} \mathrm{~s}^{-1}$ respectively, which was identical with literatures. For example, Jing reported $r_{2}$ of $\mathrm{Fe}_{3} \mathrm{O}_{4}$ nanoparticles rose from approximately 173.37 to $248.89 \mathrm{mM}^{-1} \mathrm{~s}^{-1}$ as the size increased, and they were all higher than that of the well-known commercial MRI contrast agent Feridex (127.48 $\left.\mathrm{mM}^{-1} \mathrm{~s}^{-1}\right)$ with smaller core size (about 4.8 $\mathrm{nm}) .{ }^{9}$ So USPIOs@Dex-WSG have the sufficient relaxivity as a MRI contrast agent might due to their appropriate core size of $\mathrm{Fe}_{3} \mathrm{O}_{4}$ crystal (about $7 \mathrm{~nm}$ ). Besides the core size, the $\mathrm{Fe}_{3} \mathrm{O}_{4}$ clustered condition within the dextran matrix potentially led to the confinement-driven enhanced magnetic relaxivity, so it was another influence factor for relaxivity coefficient. ${ }^{26}$ Then, $r_{2}$ of USPIOs@Dex with more $\mathrm{Fe}_{3} \mathrm{O}_{4}$ cluster was higher than USPIOs@Dex-COOH and USPIOs@Dex-WSG as shown in Fig. 11c. Longitudinal relaxation rate $\left(r_{1}\right)$ of USPIOs@Dex-WSG was also shown in Fig. 11c. Comparing with the $r_{1}$ in the reports for iron oxide nanoparticles of $T_{1}$ contrast agents, ${ }^{27} r_{1}$ (3.41 $\left.\mathrm{mM}^{-1} \mathrm{~s}^{-1}\right)$ was much less than $r_{2}\left(229.70 \mathrm{mM}^{-1} \mathrm{~s}^{-1}\right)$, which demonstrated $T_{1}$ contrast efficiency is lower than $T_{2}$ for USPIOs@Dex-WSG, so the modified USPIOs were $T_{2}$ contrast agent.

Furthermore, due to the concentration dependence of contrast enhancing effect as shown in Fig. 11b, targeting aggregation for tumor could increase the concentration in tumor areas, and reduce the dosage to decrease the possible damages caused by excessive iron intake. 


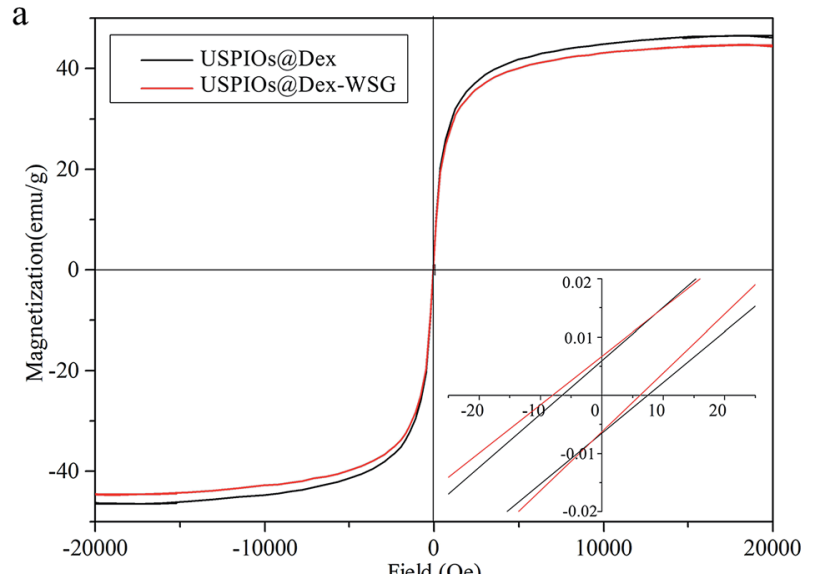

b

USPIOs@Dex ( $\mathrm{T}_{2}$-weighted)

\section{USPIOs@Dex-COOH} ( $\mathrm{T}_{2}$-weighted)

\section{USPIOs@Dex-WSG} ( $\mathrm{T}_{2}$-weighted)
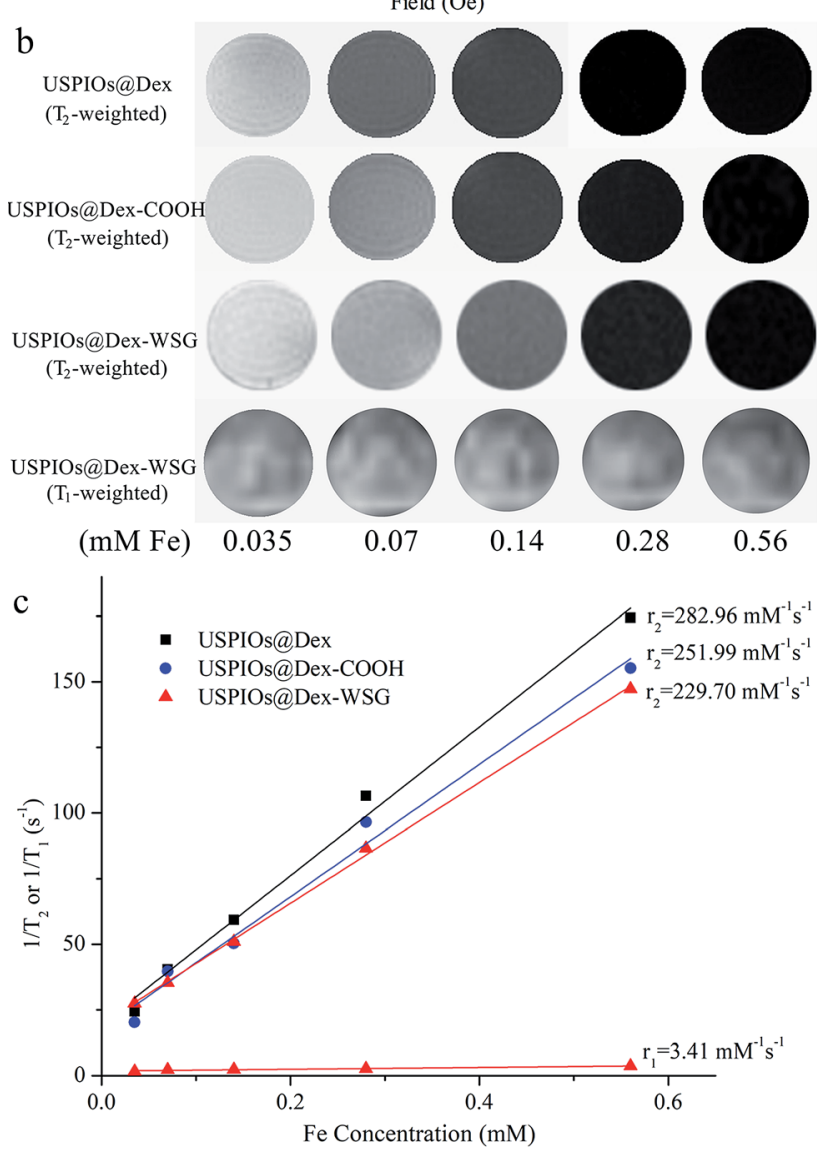

Fig. 11 Hysteresis loops of USPIOs@Dex and USPIOs@Dex-WSG (a); a series of $T_{2} / T_{1}$-weighted MRI images of USPIOs with different Fe concentration (b) and $T_{2} / T_{1}$ relaxation rates as a function of iron concentration (c).

For the application of MRI contrast agent, the cytocompatibility and targetability of USPIOs@Dex-WSG were significant. The MTT assays were carried out to evaluate the influences of synthesized USPIOs@Dex-COOH on the viability of the HUVECs and the results were exhibited in Fig. 12a and b. After cocultured with USPIOs@Dex-COOH and USPIOs@Dex-WSG for $12 \mathrm{~h}, 24 \mathrm{~h}$, and $36 \mathrm{~h}$, the viabilities of HUVECs were not obviously influenced by them because of the well-cytocompatibility of dextran. However, results of MTT assay in Fig. 12d further demonstrated that USPIOs@Dex-WSG could obviously inhibit
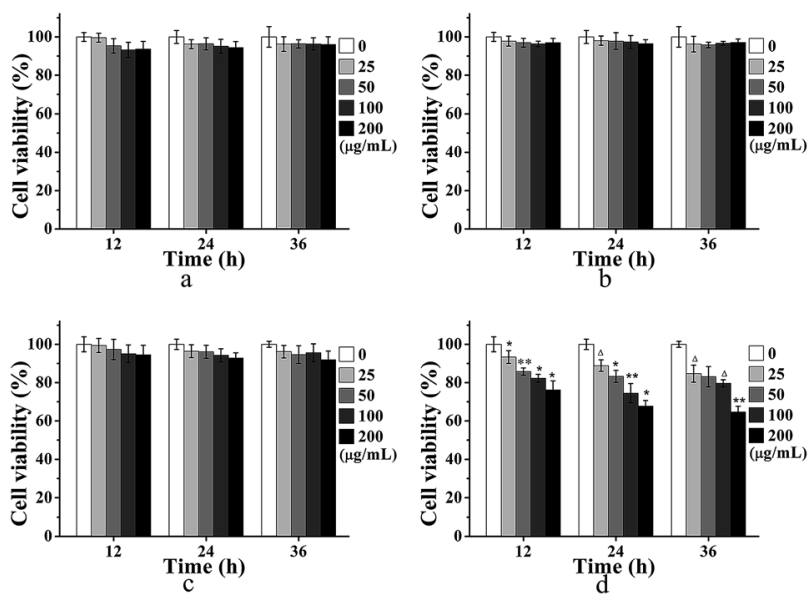

Fig. 12 Cells viability of HUVECs upon incubation with USPIOs@DexCOOH (a) and USPIOsaDex-WSG (b), SKOV-3 cells with USPIOsaDex-COOH (c) and USPIOs@Dex-WSG (d) with Fe concentration of 0 , $25,50,100$ and 200 ( $\mu \mathrm{g} \mathrm{Fe}$ ) $\mathrm{mL}^{-1}$ as determined by MTT cell viability assays. Data were presented as means $\pm \operatorname{SD}(n=3)$, * shows $p<0.05$, ** show $p<0.01$ and $\Delta$ shows $p<0.001$.

the proliferation of SKOV-3 cells in both time and dose dependent manners, and a significant decrease $(p<0.001)$ of cell viability could be obtained after $36 \mathrm{~h}$ of incubation with USPIOs@Dex-WSG at iron concentration of $200(\mu \mathrm{g} \mathrm{Fe}) \mathrm{mL}^{-1}$. Meanwhile, the USPIOs@Dex-COOH showed negligible toxic effect (viable cells $>90 \%$ ) even at iron concentration of $200(\mu \mathrm{g}$ Fe) $\mathrm{mL}^{-1}$ as shown in Fig. 12c. These results suggest that the USPIOs@Dex-WSG could inhibit proliferation of SKOV-3 cells and start the tumor cell apoptosis process, with no cytotoxicity to HUVECs. ${ }^{18}$

Meantime, the targetability of USPIOs@Dex-WSG was further verificated by the Prussian blue staining as shown in Fig. 13. A strong binding between the USPIOs@Dex-WSG and the SKOV-3 cells was observed (Fig. 13f), whereas there was no significant combination for USPIOs@Dex-COOH (Fig. 13c). However, there was only slight combination between the USPIOs@Dex-WSG and the L929 and HUVEC cells selected as the comparison (Fig. 13d and e).

In our previous work, peptide-WSG was screened out by in vitro and in vivo phage display, and it was detected to locate in cytoplasma and nucleus of SKOV-3 cells by immunofluorescence. Peptide-WSG could competitively inhibit cellular adhesion molecules on the SKOV-3 cell membrane and target to corresponding receptors, then bind to nucleus through the cell membrane, so USPIOs@Dex-WSG could induce SKOV-3 cell death in the in vitro study as demonstrated in Fig. 12d. And the results of Prussian blue staining suggested that USPIOs@Dex-WSG could specifically bind to SKOV-3 cells under the mediation of conjugated peptide-WSG, while they are not bind to HUVECs. Thus, USPIOs@Dex-WSG would exhibit the targetability to the tumor cells, and could be considered as an ideal candidate for ovarian cancer targeting MRI contrast agent. ${ }^{13,18}$ Nevertheless, this targetability might need to be further verified in vivo. ${ }^{28}$

In order to research the difference in blood circulation time between USPIOs before and after modification, the plasma half- 

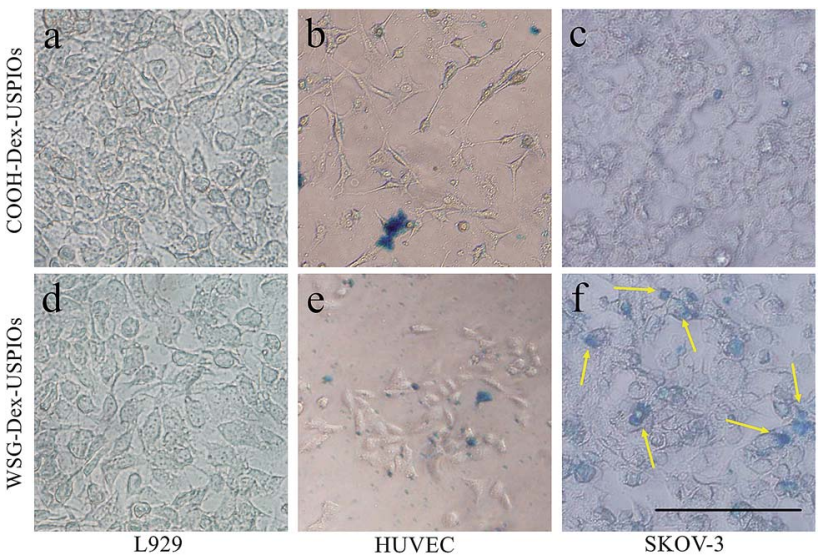

Fig. 13 Prussian blue staining of USPIOsaDex-COOH and USPIOs@Dex-WSG incubation with L929, HUVEC and SKOV-3 cells. Scale bar represents $100 \mu \mathrm{m}$.

life $\left(t_{1 / 2}\right)$ of iron content was calculated with the curve fitted by single exponential decreasing function as shown in Fig. 14, $t_{1 / 2}$ of USPIOs@Dex and USPIOs@Dex-WSG were 7.1 h and $10.6 \mathrm{~h}$ respectively. Numerous studies have shown that the surface potential and hydrophobicity of nanoparticles could affect their interaction with proteins in the blood, thereby changing their blood circulation time. Relatively speaking, nanoparticles with bigger size, stronger surface potential and higher hydrophobicity could be more easily adsorbed with negatively charged protein molecules in the blood, which would be recognized and removed by RES. Therefore, USPIOs@Dex-WSG nanoparticles, which were smaller, more hydrophilic and had a small amount of negative charge than USPIOs@Dex, had a longer blood circulation time. This would be beneficial for more USPIOs to achieve the tumor sites, and USPIOs@Dex-WSG could target to corresponding receptors of SKOV-3 cells and gather in tumor. For the concentration dependence of contrast enhancing effect, the long blood circulation time and tumor targetability of USPIOs@Dex-WSG would suitable for the use of MRI contrast agents.

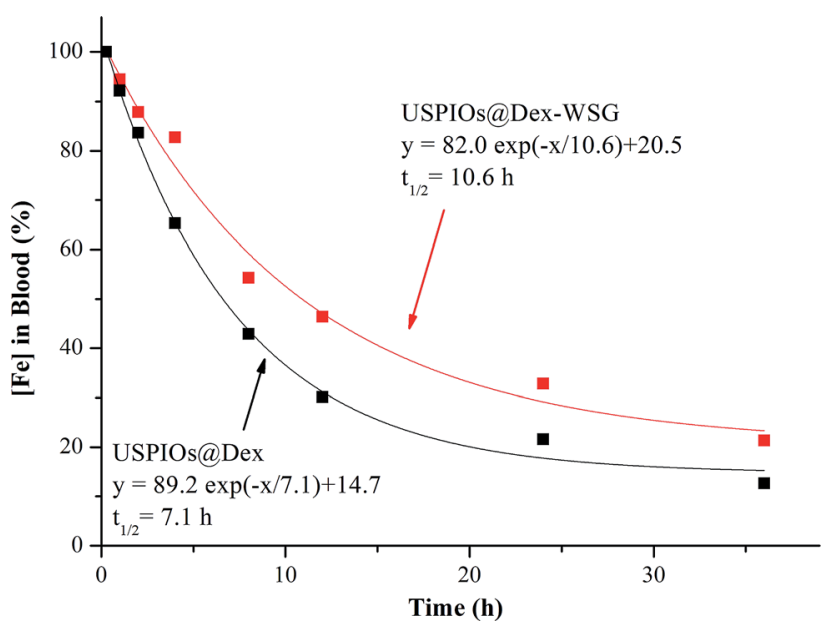

Fig. 14 Percentage of USPIOs@Dex-WSG and USPIOs@F127-WSG remaining in blood circulation as a function of time.

\section{Conclusions}

A novel dextran wrapped USPIO was synthesized with a welldesigned co-precipitation procedure in which the biocompatible dextran played the dual roles of the grain inhibitor and the cladding agent, and the sodium citrate was applied to carboxylize the hydroxyls of dextran molecules via the esterification reaction, and then tumor targeting peptide-WSG was grafted to the carboxyl groups by the EDC method. Then, the hydrophilicity of particles was enhanced, the USPIOs@Dex-WSG would have the ability to evade from eliminated by RES more easily and prolong residence time in blood circulation. USPIOs@DexWSG were superparamagnetic with the saturation magnetization of $44.65 \mathrm{emu} \mathrm{g}^{-1}$, and with high transverse relaxivity as the $R_{2}$ relaxivity coefficient value of $229.70 \mathrm{mM}^{-1} \mathrm{~s}^{-1}$ which met the requirement of MRI contrast. Furthermore, USPIOs@Dex-WSG exhibited nontoxicity for normal cells as L929 and HUVECs, and were specifically targeted to the SKOV-3 cells. Thus, the novel dextran wrapped and WSG-peptide grafted USPIOs have potential to be applied as the tumor active targeting contrast agent for MRI.

\section{Conflicts of interest}

We declare that we have no financial and personal relationships with other people or organizations that can inappropriately influence our work, there is no professional or other personal interest of any nature or kind in any product, service and/or company that could be construed as influencing the position presented in, or the review of, the manuscript entitled.

\section{Acknowledgements}

This work has been supported by the National Natural Science Foundation of China (Project No. 51372157); Scientific and Technological Funds from Education Department of Sichuan Province (No. 15ZB0209); Key Scientific and Technological Funds from Zigong City (No. 2016XC11), Sichuan Science and Technology Program (No. 2017JY0255).

\section{Notes and references}

1 M. Ye, Y. Qian, J. Tang, H. Hu, M. Sui and Y. Shen, J. Controlled Release, 2013, 169, 239-245.

2 L. Liu, Q. Ye, Y. Wu, W. Y. Hsieh, C. L. Chen, H. H. Shen, S. J. Wang, H. Zhang, T. K. Hitchens and C. Ho, Nanomedicine, 2012, 8, 1345-1354.

3 R. Ahmadia, M. Malekb, H. R. M. Hosseinia, M. A. Shokrgozarc, M. A. Oghabiand, A. Masoudia, N. Gue and Y. Zhange, Mater. Chem. Phys., 2011, 131, 170-177.

4 H. Yang, C. Zhang, X. Shi, H. Hu, X. Du, Y. Fang, Y. Ma, H. Wu and S. Yang, Biomaterials, 2010, 31, 3667-3673.

5 G. H. Ima, S. M. Kim, D. G. Lee, W. J. Lee and J. H. Lee, Biomaterials, 2013, 34, 2069-2076.

6 J. Yang, Y. Luo, Y. Xu, J. Li, Z. Zhang, H. Wang, M. Shen, X. Shi and G. Zhang, ACS Appl. Mater. Interfaces, 2015, 7, 5420-5428. 
7 H. T. Ta, Z. Li, C. E. Hagemeyer, G. Cowin, S. Zhang, J. Palasubramaniam, K. Alt, X. Wang, K. Peter and A. K. Whittaker, Biomaterials, 2017, 134, 31-42.

8 M. Kallumadil, M. Tada, T. Nakagawa, M. Abec, P. Southern and Q. A. Pankhurst, J. Magn. Magn. Mater., 2009, 321, 15091513.

9 J. Huang, L. Bu, J. Xie, K. Chen, Z. Cheng, X. Li and X. Chen, ACS Nano, 2010, 12, 7151-7160.

10 C. Ansari, G. A. Tikhomirov, S. H. Hong, R. A. Falconer, P. M. Loadman, J. H. Gill, R. Castaneda, F. K. Hazard, L. Tong, O. D. Lenkov, D. W. Felsher, J. Rao and H. E. Daldrup-Link, Small, 2014, 10, 566-575.

11 E. Cheraghipour, A. M. Tamaddonb, S. Javadpour and I. J. Bruce, J. Magn. Magn. Mater., 2013, 328, 91-95.

12 A. S. Wadajkar, J. U. Menon, Y. S. Tsai, C. Gorec, T. Dobin, L. Gandeec, K. Kangasniemi, M. Takahashi, B. Manandhar, J. M. Ahn, J. T. Hsieh and K. T. Nguyena, Biomaterials, 2013, 34, 3618-3625.

13 Y. Zhang, Z. Huang, Z. Wu, G. Yin, L. Wang and F. Gao, Colloids Surf., B, 2016, 140, 437-445.

14 S. A. Pour and H. R. Shaterian, J. Mater. Sci.: Mater. Med., 2017, 28, 91.

15 R. Chaa, J. Lia, Y. Liu, Y. Zhang, Q. Xie and M. Zhang, Colloids Surf., B, 2017, 158, 213-221.

16 H. Zuo, W. Yao, T. Chen, J. Zhu, J. Zhang, Y. Pu, G. Liu and X. Zhang, BioMed Res. Int., 2014, 852352.

17 S. Zheng, M. Huang, R. Hong, S. Deng, L. Cheng, B. Gao and D. Badami, J. Biomater. Appl., 2014, 28, 1051-1059.
18 C. Ma, G. Yin, D. Yan, X. He, L. Zhang, Y. Wei and Z. Huang, J. Pept. Sci., 2013, 19, 730-736.

19 Z. Wang, R. Qiao, N. Tang, Z. Lu, H. Wang, Z. Zhan, X. Xue, Z. Huang, S. Zhang, G. Zhang and Y. Li, Biomaterials, 2017, 127, 25-35.

20 M. Nidhin, S. S. Nazeer, R. S. Jayasree, M. S. Kiran, B. U. Naira and K. J. Sreeram, RSC Adv., 2013, 3, 6906-6912.

21 A. Saraswathy, S. S. Nazeer, N. Nimi, S. Arumugamb, S. J. Shenoyc and R. S. Jayasree, Carbohydr. Polym., 2014, 101, 760-768.

22 A. E. Beeran, F. B. Fernandez, S. S. Nazeer, R. S. Jayasree, A. John, S. Anil, S. Vellappally, A. A. A. Al Kheraif and P. R. H. Varma, Colloids Surf., B, 2015, 136, 1089-1097.

23 A. E. Beeran, S. S. Nazeer, F. B. Fernandez, K. S. Muvvala, W. Wunderlich, S. Anil, S. Vellappally, M. S. R. Rao, A. John, R. S. Jayasree and P. R. H. Varma, Phys. Chem. Chem. Phys., 2015, 17, 4609-4619.

24 A. Saraswathy, S. S. Nazeer, M. Jeevan, N. Nimi, S. Arumugam, V. S. Harikrishnan, P. R. H. Varma and R. S. Jayasree, Colloids Surf., B, 2014, 117, 216-224.

25 N. Nimi, A. Saraswathy, S. S. Nazeer, N. Francis, S. J. Shenoy and R. S. Jayasree, Biomaterials, 2018, 171, 46-56.

26 T. D. T. Nguyen, A. Pitchaimani, C. Ferrel, R. Thakkar and S. Aryal, Nanoscale, 2018, 10, 284-294.

27 Y. Bao, J. A. Sherwood and Z. Sun, J. Mater. Chem. C, 2018, 6, 1280-1290.

28 C. Zhou, H. Wu, M. Wang, C. Huang, D. Peng and N. Jia, Mater. Sci. Eng., C, 2017, 78, 817-825. 